\title{
El Secretario de las Corporaciones locales ante las nuevas tendencias de la Administración
}

La Administración local, como toda la Administración, experimenta actualmente una transformación radical por la incorporación a la técnica administrativa de otras técnicas que procedentes del campo laboral o del de la empresa privada han adquirido ya carta de naturaleza con la instauración de sistemas gerenciales $\mathrm{y}$ de oficinas de coordinación $\mathrm{y}$ de racionalización del trabajo.

Por ello es interesante estudiar la faceta propiamente profesional del Secretario a la vista de las modernas concepciones del Municipio no sólo en España, sino en el extranjero. Priva hoy día el concepto de gerencia aplicado $\dot{a}$ la Administración municipal, hasta el extremo de que ya hace tiempo se ha dicho que cuna moderna Ciudad es, no tanto un Estado en miniatura como una empresan (Dillon). Ese concepto del Municipio como empresa quizá pueda ser exagerado; en efecto, 1a Ciudad es algo más, pero el régimen administrativo de aquélla debe parecerse cada vez más al de las grandes entidades industriales o comerciales, aunque como dice Reed: "Hay algunas personas, no $\sin$ influencia, que se molestan aparentemente por la aplica- 
ción de la gerencia al campo del gobierno. Creen que el sistema de gerencia aceptable en el campo comercial, implica en lo político, algo dictatorial, la subordinación de los representantes del pueblo a los burócratas. Ignoran aquéllos la verdadera distinción entre las funciones de representación y la Administración, entre la determinación política y la ejecución de esa política». Estos conocimientos doctrinales se reflejan perfectamente ya no sólo en el gobierno de las ciudades americanas, sino que van invadiendo el campo de la Administración local del mundo entero, y el concepto de gerencia en los negocios municipales adquiere categoría casi universal. Pero, volvemos a recalcar aquí que no quieren significar nuestras palabras que lo que sea universal sea el sistema americano de gobierno por Gerente, a lo que nos referimos es a ese concepto gerencial de la Administración, si bien entendemos; como Pfiffner, que entre Administración y gerencia no existe disparidad, "la primera se refiere a actividades de gobierno técnicas, no políticas, y la última está más intimamente ligada con la coordinación de esas actividades". Brownlow sostiene un punto de vista parecido pero recalcando que la gerencia nunca debe perder de vista el objetivo que persigue la empresa $u$ operación que se realiza.

$\mathrm{Y}$ es sencillamente que el fenómeno de la transformación del antiguo concepto de administración por el más moderno y quizá más dinámico de gerencia, repetimos, va adquiriendo caracteres de universalidad, porque al fin y al cabo es "la primacía de lo funcional sobre lo natural o históricon a que hace referencia Ruiz del Castillo. Así vemos que merced a la interpretación que en la esfera municipal se va dando a las palabras administración y gerencia, tratando de lograr una simbiosis, se va transformando indudablemente la ciencia administrativa que, como recuerda Goodnow, fué llamada despectivamente en los primeros tiempos "el estudio de las alcantarillas", pero que fué un medio acertadísimo para llegar al concepto moderno de la Administración, ya que, la extraordinaria expansión presente del estudio de la Administración pública ha sido consecuencia en muchas instituciones del estudio de las funciones muniripales. La Administración municipal, aunque es parte de la Administra- 
ción pública, es más Administración, es como si dijéramos la avanzàda de 'a Administración, y ello es por ese elemento gerencial que la califica y por la mayor aproximación del adminiṣtrador al administrado.

Funciones gerenciales verdaderamente tales son las que, según nuestros reglamentos vigentes, competen al Secretario de las Corporaciones locales. "Efectivamente dirige los negocios municipales el que ejerce la gerencia, pero este concepto es más administrativo, no hay que mezclarlo o confundirlo con el de Jefe político, con el de Jefe del gobierno municipal; a los órganos políticos corresponde la formulación de los principios, y la determinación de las directrices del gobierno local, pero la ejecución de esos acuerdos es el verdadero objeto de la gerencia municipal" a cargo del Secretario de la Corporación. La gerencia, dice Reed, “es una vocación, profesión o arte que requiere conocimientos especializados, la perfección en ella no puede adquirirse si no es por la experiencian. En este sentido la aceptamos nosotros como dirección permanente de todos los elementos o factores que intervienen en el gobierno local, pero llevada a cabo por medios administrativos, no políticos, y que por sí sola constituye una técnica, y'a este concepto nos referiremos siempre que a to largo de este trabajo hablemos de gerencia municipal.

Como hemos dicho anteriormente, el célebre municipalista norteamericano Reed, dice que cla gerencia es una vocación, profesión o arte que requiere conocimientos especializados", quien la ejerza, Gerente o Secretario, el nombre es lo de menos, ha de ser forzosamente un funcionario profesional; su reclutamiento, su formación. y sus cualidades no es tarea fácil el definirlas, o señalarlas, por eso se ha dicho que wde la misma manera que no se puede escribir un libro que con su simple lectura pueda el lector aprender a pintar un cuadro, ganar un pleito, dirigir una tienda, una factoría o una Ciudad, la perfección en la gerencia sólo puede adquirirse por la experiencian, y más adelante veremos cómo la gerencia municipal es una profesión distinta de otras ciencias o artes que se emplean al servicio del gobierno local. El Gerente o quien hace sus veces usa de ellas 
como los hombrès usan los elementos materiales para producir el resultado requerido (medios psicolćgicos en la selección de personal, físicos para la construcción de puentes, sanitarios para la protección de la saíad). Quizá el Gerente requiera a veces algunos conosimientos especializados en algunas materias técnicas, pero no será lo general ; por eso decía Posada, que "la dirección municipal de una Ciudad de vida un tanto complicada, pide en quien haya de asumirla condiciones de muy diversa índole, y por de pronto difíciles de fijar todas ellas".

No cabe duda que la primera condición del Secretario ha de ser su preparación, ha de tener especialmente una gran preparación en. las materias básicas de la Administración, unida, eso sí, a una gran experiencia en los asuntos de la Ciudad o del Nínicipio rural porque cada uno de éstos tiene su técnica, puesto que tienen sus características especiales y múltiples problemas que plantea a quienes los rigen. Pero esto no basta, la preparación y la experiencia son mucho, mas no son todo, pues como dice Munro, wmuchos Gerentes nombrados tan sólo en atención a sus condiciones técnicas han demosirado su falta de aptitud, por defecto de las condicicnes personales necesarias", y, añade Posada, qua sdebe se: un lomise preparacio en la ciencia y en el arto kie gobernar".

Ia discreción ha de ser wna cwalidad esencial ciel Secretario, porca colocado en in planc elevacio en el gobierno del Municipic en él han de estar siempre fijas las miradas de los administrados y de la Corporación que los aciministra, y no debe olviciar aquellos múltiples consejos que nuestro Baltasar Grasián escribiera en "El Discreto", y que pone en boca del Rey Don Fernardo: "Sea uno, decía, señor de sí y lo será de los demás. La deterción sazora 'os aciertos y madura los secretos; que la aceleración siempre pare hijos abortivos, sin vida de inmortalidad. Ha de pensar despacio y ejecutar presto; ni es segura 1a, diligencia que nace de la tardanza. Tan presto como alcanza las cosas se le rasu de las manos; que a veces el estampido de! cae. fué aviso del haber tomadon.

Hes de ser magnámisno, er el sertido que a esła pala: Ortegz y Gasset, cuando dice: "El magnánimo es un hombzo 
que tiene visión creadora, vivir y ser es para él hacer grandes cosas, producir obras de gran calibre", y ello io debe hacer aun a sabiendas de la murmuración y de que los que ignoran la verdadera distinción entre administración y política, le tachen de político, porque el Secretario ha de ser dinamismo, dirección permanente $\mathrm{y}$ energía creadora si no quiere caer en la rutina, el anquilosamiento profesional $y$, en definitiva, en el fracaso y en el descrédito.

El Secretario debe ser accesible. Para evitar ofensas uno debe ser cortés y el principal aspecto de la cortesía es ser accesible. "No siempre se ha de reir con Demócrito ni siempre se ha de llorar con Heráclito", dice Gracián, y añade: "Haya vez para lo serio y también para lo humano", "hora propia y hora ajena", como queriendo indicar en nuestro caso que el Secretario no ha de encastillarse en sus conocimientos y en su técnica, tiene que ser humano y presentarse como tal ante el público $y$ ante la Corporación, pues si aquél no le entiende es peor que ésta le tilde de pedante.

El principio de lo honradez ha de prevalecer en todos sus actos si el Secretario quiere pisar siempre terreno firme, pues en este aspecto el más ligero resbalón puede originar un vertiginoso descenso y hasta terminar en una aparatosa caída.

En sus relaciones con la. Corporación es fundamental el deber de lealtad, pero no sólo de lealtad para con dicha Corporación, sino también de lealtad para consigo mismo, y para con la función que se le ha encomendado y el Cuerpo a que pertenece. En los Estados Unidos se ha dictado un Código de Etica, por la "International CITY Managers Association", en donde se dice que "el podér entraña responsabilidad y la responsabilidad demanda poder, y el Gerente que resulta impotente para inspirar apoyo; debe dimitir". "Por desgracia, dice Reed, algunos Gerentes de Corporaciones conservan sus cargos por doblegarse a los dẹseos del Consejo, aun a sabiendas de que están equivocados, pero esto suele ser a costa de su reputación profesional y al final, pueden perder el cargo a manos de aquellos a quienes quisieron halagarn. Esto es una gran verdad, que la experiencia de.este autor norteamericano avala con su autoridad. El 
Secretario no debe doblegarse a los deseos de los políticos que componen el Consejo, la Corporación o el Ayuntamiento, sin antes estudiar detenidamente las consecuencias de tal entrega. "A veces estos funcionarios someten la buena administración a los deșeos políticos de la Corporación, dice el mismo Reed, pero en tales casos a lo sumo consiguen un buen empleo particular para algunos años, mas en su profesión y en su conciencia raramente serán una gran figuran. Hay que esperar con paciencia el momento oportuno, no ser estridentes, pero sí ser hábiles, para guardar al mismo tiempo, como dice el mismo autor citado, "el cargo y el respeto a sí mismo». El Secretario debe ser, pues, leal con la Corporación y tener muy presente que la Administración debe actuar siempre bajo las directrices que le señala la política, mas esto no quiere decir jamás que tenga que ser un hombre de paja, o un comparsa. Sus conocimientos técnicos le obligan a asesorar debidamente a la Corporación, y hacer valer su opinión cuando ello vaya en beneficio del Municipio y de sus habitantes. Todos sabemos que esto es muy difícil en la práctica, pero no es imposible, y si el Secretario es hábil y recto lo logrará, sin grave quebranto, en el seno de la Corporación.

Es oportuno el recalcar aquí unas frases de este autor americano a que me vengo refiriendo, y que por haber sido Gerente de varias ciudades norteamericanas (cargo muy similar al del Secretario español), tienen un gran valor porque plasman muchos años de experiencia profesional. Dichas palabras son las siguientes: "Claro está que un Gerente no puede ejercer su función sin una cierta dosis de jefatura politica, pero en el mejor sentido de la palabra, como aplicación de medios a fines, teniendo en cuenta la opinión pública. Su función no puede ser ejercida sin un conocimiento de los hombres y de las corrientes de la vida politica. Sin participar en las luchas y tendencias políticas observar atentamente lo que ocurre en derredor suyo. No debe encerrarse en su cuarı de trabajo con el pequeño grupo de sus colaboradores, sino que debe mezclarse con el pueblo para conocerle. No debe ser un profesional de la politica, pero si 
zun estudioso de la politica en interés del pueblon. Y estas palabras son perfectamente aplicables al Secretario local español.

El Secretario, en sus relaciones con el personal que tenga à sus órdenes, debe tener especial cuidado en distinguir entre las relaciones propiamente humanas y las eminentemente técnicas. El Secretario ha de conocer a sus subordinados, pero en especial a los Jefes de sus Departamentos, porque ello es presupuesto indispensable de la previsión, que ha de ser según los métodos de racionalización del trabajo la primera cualidad del administrador. Nada se debe dejar al azar, y si cada función requiere un órgano especializado para su desempeño, es evidente que ha de exigir en cada servicio una organización perfecta, y aunque dejaremos la parte relativa a las facultades de organizador del Secretario para más adelante, sí conviene decir aquí que ha de saber mandar, porque éste es otro de los factores de la buena administración que requiere además que el Jefe çoordine y fiscalice la labor de los que están bajo su mando y supervisión. Con respecto a las relaciones propiamente humanas que el Secretario ha de tener con los Jefes de Departamento y éstos con sus subordinados, nos hemos de referir a una obra muy importante por el carácter práctico de la misma escrita por Carvaiho Henriques. Este autor hace una clasificación de las cuaiidades que debe reunir el que tiene a su cargo la dirección del personal de una empresa (ya sabemos que el Municipio tiene mucho de empresa). Hay tres cualidades fundamentales, que son: $10^{\circ}$ Infundir respeto. $2 .^{\circ}$ Infundir confianza. $3 .^{\circ}$ Ganarse el afecto.

Hemos dejado para el final una cualidad fundamental que debe tener el Secretario, y es la de ser un buen organizador. Si la gerencia ha de ser dinamismo, acción, no cabe duda que tiene que existir una organización, es decir, una cierta disposición de medios personales y materiales encaminada a la más perfecta realización de la acción administrativa, porque como señala García Oviedo, la organización es antecedente obligado de la acción, y si no fuesé de máxima utilidad sería imperativo de la lógica adecuar aquélla a lás exigencias propias de la empresa administrativa. Organización y gerencia son conceptos que hay 
que distinguir. "Organización es la estructuración de los individuos y de las funciones; y gerencia, es lo relativo a la dirección de esos individuos y de sus funciones para lograr los fines determinados"; por ello, atañe especialmente al Secretario, como Jefe de los Servicios y dependencias municipales, todo aquello que, con palabras de Jordana de Pozas, se refiere a ulos problemas relativos al personal, a los locales, a las máquinas, muebles y demás cosas útiles para la actividad administrativa; a la división y organización de funciones y servicios $\mathrm{y}$, finalmente, a los métodos seguidos en la práctica y gestión de los mismosn.

En su magnífico tratado sobre la racionalización del trabajo, señala el autor belga Leener cuáles deben ser los objetivos de la organización.

Partiendo de la base de que no podemos admitir la misma importancia en todos ellos, ya que ésta varía aunque no sea más que al distinguir en las administraciones públicas y en las privadas, señala dicho autor como fundamentales objetivos los siguientes :

a) La economía de personal.

b) La cconomía de materiales.

c) La economía de utillaje.

d) La economía de espacio.

c) La reducción de los riesgos.

f) La visión de conjunto, y

g) La importancia, en general, del factor tiempo.

Yo recomendaría a todos los Secretarios, Interventores y Depositarios de Administración local, que dedicaran especial cuidado a los problemas de la racionalización del trabajo, porque del estudio de esta materia se pueden llevar a la práctica conclusiones que beneficien grandemente al público. El Secretario no debe tener otra preocupación más importante que la de poner los servicios en las mejores condiciones para el público. En distinta escala, ya se trate de Municipios rurales, medianos o de grandes ciudades, siempre cabrá la modernización de los métodos de trabajo y el control de los diferentes y complicados servicios a su cargo, ya mediante la petición de partes diarios, ya 
solicitando memorias o informes de jos diferentes servicios para luego, e: esa especie de laboratorio que debe ser su despacho, observar, comparar y deducir datos con vistas a una continua transformación y mejoramiento de las condiciones en que se prestan los diferentes servicios. El Secretario no ha de tener en esto prejuicios. Sabemos cuánto se censura a la burocracia y se critica lo que se llama ell afán desmedido de complicar la administración, pero la realidad es que por esta labor de estadística y de control, cada vez la vida se alarga más, los accidentes se previenen mejor y la administración se perfecciona de día en dia. Claro está que esta labor estadística de revisión y de control no se puede abandonar un solo momento, porque la negligencia en servicio de tal importancia ocasionaría la ineficacia no sólo de su labor, sino del trabajo de los órganos subordinados que envían sus datos no para que vayan al cesto de los papeles sin ser mirados, sino para ser clasificados, estudiados y transformados en beneficiosas decisiones. Un buen sistema de organización del trabajo que mediante la eliminación de pérdidas de tiempo en el mismo, la utilización de impresos, máquinas, etcétera, reduzca los gastos de personal, no sólo sin restarle eficacia, sino aumentándole, si es posible, será siempre para el Secretario un éxito más ostensible que cualquier otro. Dentro de los principios generales de la organización hemos de señalar para el Secretario, como fundamental, aparte de los de jerarquía y división departamental, el de la coordinación. Decía Fayol que "donde no se coordina nadie piensa en el interés generalı. En efecto, la coordinación es de tal importancia para el Secretario que ya puede éste tener muy bien estructurados los medios personales y materiales de que dispone, pero como no coordine sus funciones, el servicio no marchará, ya que sin coordinación no hay verdadera administración. La coordinación es, pues, un factor indispensabile de la gerencia, de tal importancia que casi podría decir que tiene categoría propia, o que por lo menos la califica, pues la gerencia no se concibe sin una facultad coordinadora. Comprendemos que no siempre se entendió así, pero la verdad es que tampoco hasta hace relativamente escaso 
tiempo se llegó a distinguir claramente ia organización y la gerencia como elementos funciamentales de la administración.

Pero, ¿ cómo se cooráina'?, ¿ qué métodos coordinadores serán más eficaces? No puede darse una contestación categórica porque iantos pueden ser los sistemas de coordinación como motivos den lugar a la misma. En unos casos será la presencia en cacia Departamento de un funcionario encargado de tal misión, como vemos utilizar en iriglaterra, con el sistema ce corganiza ción y métodos"; en otros casos la junta semanal o por lo menos periócicamente regular de los Jefes de Departamento cor el Gerente o Jefe superior administrativo. Este último es un procedimiento muy eficaz porque en esas reuniones además de que los inferiores tengan relación y contacto con sus superiores y éstos con aquéllos, aprendiendo todos algo que no sabian, se consigue la formación de un "espíritu de equipo" y es la manera de que todos los Departamentos se den una perfecta cuenta de que forman parte de un todo, que es la Corporación. Considera Pfiffner que el Gerente debe "ver, entender y conocer el proceso de la gerencia municipal a la vez como un todo y sus partes. Tal conocimiento le habilitará para actuar en interés de la coordinación, la armonía y la economían.

La función asesora del Secretario puede influir y de hecho influirá de manera notoria en la coordinación de las decisiones de la Corporación o de sus Comisiones o Juntas porque este funcionario, que probablemente conoce mejor que nadie la situación de los probiemas municipales, puede de antemano prever las consecuencias de las decisiones del cuerpo que gob:erna a la Ciudad y evitar resoluciones contradictorias al sentido unificador que debe presidir toda verdadera y perfecta gerencia.

He querido señalar en el curso de esta modesta: exposición las características funciamentales cie la función encomendada a los Secretarios de las Corporaciones locales, bajo un punto de vista moderno, habiando de gerencia más que de administración, porque estimo que el dinamismo que caracteriza a la gerencia y el gracio de responsabilidad que incumbe a su tivilai sor más adecuadas a las funciones que le encomienca la ley 7 los reglamentos al Secretario local español que la simpla de- 
nominación de Administración municipal. Quizá se diga que los Gerentes norteamericanos son, como los Burgomaestres alemanes, más parecidos en su misión a los Alcaldes españoles que a los Secretarios de Administración local. Yo no lo creo así; es más, creo firmemente que con una interpretación amplia de los preceptos reglamentarios vigentes, especialmente del párrafo 6 . $^{\circ}$ del artículo 141 y de aquel otro del artículo 144 del Reglamento de funcionarios locales, que dice que gel Secretario debe adoptar las medidas necesarias para la coordinación de todas las dependencias a fin de lograr la más perfecta actuación conjunta y el exacto cumplimiento de las disposiciones legales y de los acuerdos adoptados" se puede llegar a conceder al Secretario la investidura de verdadero Gerente. Si nos fijamos en las funciones de los Gerentes de las ciudades americanas, veremos que, por ejemplo, en la Carta de Dayton se señalan al Gerente atribuciones que como la aejecución de los servicios ordenados por la Carta", "la facultad de tomar parte en las discusiones de la Comisión sin derecho a voto", el "poder hacer a la Comisión recomendaciones de proposiciones que le parezcan necesarias y útiles", "la dirección del personal de todas las dependencias municipales" y el "control de todos los servicios existentes" que son casi idénticas a las funciones del Secretario municipal en España, porque, entre nosotros el carácter de fedatario, que no se da en los Gerentes y que es quizá el más antiguo y hasta hace poco el más característico del cargo de Secretario, ha venido quedando relegado a segundo término ante el desarrollo insospechado de los servicios públicos que requieren una gestión adecuada y eficaz y necesitan de una gerencia que coordine y ejecute lo que el Ayuntamiento aprobó.

Vemos, pues, que hay más analogía entre el cargo del Gerente norteamericano y el de Secretario español, que entre Gerente y. Alcalde, porque en España el Alcalde, que es el Jefe superior de la Administración municipal, y es al mismo tiempo representante del Gobierno en el término, tiene un carácter eminentemente político, mientras que el Gerente es un profesional, como to es el Secretario.

$\mathrm{Y}$ no es sólo en Norteamérica, en la misma Inglaterra, ên 
donde el carácier represeriai:\%o ju úemocrático cie las Corporaciones locales no puece porerse en duda, las funciones del Town Clerk, el Secretario, soii de tal importancia que iada tendrían que envidiar a las de aquellos países en donde el principio de la eficacia ha prevalecido sobre el de la democracia. A propósito ce este funcionario inglés es sintomático lo que de él dice un conocido alitor compatriota suyo, Mr. Jackson: "El Secretario de una Corporáción local es el funcionario administrativo supericr. Tiene algo del carácter o funciones do $2 ! n$ gercinie o direcior de una gran empresa que tenga varios ciepartamentos, caria wno de los cuales tiene su drector propio. La principai misión de un Secretario er la administración die una moderna Corporación local, es guiar, infuir y dirigir toda la organización y su actuación de acuerdo con los poderes legales y los deberes de la Corporación y de acuerdo con la política desarrollada por el Consejo y sus Comités. Es el capitán del equipo de direciores de departamento, se presenta como una especie de ponente o relator antre los miembros de la Corporación y de la máquina oficial; él es el portavoz oficial del Consejo en sus relaciones con eí públicc, en general y con el nodér central, es el supremo coordinador; es la persoria a la cual se escribe si ustedes quieren comtnicarse con la Corporación local; lleva la principal corresponciencia ofícial diel Consejo, tiene asiento en la Cámara de sesiones y ya por si o po: medio de un representante atiende a tocos los Comités y asesora al Consejo y a los Comités sobre cuál es el procedimiento a seguir en la conducción de los asuntos. El prepara el orden del día de cada sesión, redacia las actas del Consejo y Comités y custodia los archivos y registros de la Cornoración".

En Alemania, en la zona que esiuvo ocupada por los ingleses (Rhin-West́falia) se modifica algo 1a organización tradicional, donde el Burgomaestre riofesional era la característica fur:damental, para crear el cargo de Director del Municipio (Gemeindedirektor), que tiene funciones de verdadero Gerente.

Como se ve Gerentes, Directores y Secretarios, ya sea en Nortcariéricu, en Alemania, en Inglaterra o en España, tienen funciones my similares y ello es debico sin duda aìguna a esa 
evolución que se ha experimeitado.en el concepto del Municipio y de la Ciudad al considerarios, si no como una empresa, sí como algo muy parecido a una empresa.

Las nuevas tendencias de la Administración para hacerla cada vez más técnica, coordinando decisiones, racionalizando el trabajo y dotándole de un impulso gerencial son campo abierto al estudio y aplicación de los funcionarios pertenecientes a los Cuerpos nacionales de Administración loçal.

Jaime Pereira García

Diplomado en Administración Local 